\title{
Miconia Ruiz \& Pav. no Núcleo Curucutu, Parque Estadual da Serra do Mar, Estado de São Paulo, Brasil
}

\author{
Adenilsa Aparecida Rodrigues-Lima ${ }^{1,3}$ e Paulo Affonso ${ }^{2}$
}

Recebido: 8.04.2015; aceito: 16.12.2015

\begin{abstract}
Miconia Ruiz \& Pav. in Núcleo Curucutu, Parque Estadual da Serra do Mar, São Paulo State, Brazil). This paper consists of a survey of the Miconia Ruiz \& Pav. (Melastomataceae) in Núcleo Curucutu, Parque Estadual da Serra do Mar, São Paulo State, Brazil. Nine species of Miconia were recorded: M. cabucu Hoehne, M. chartacea Triana, M. cinnamomifolia (DC.) Naud., M. cubatanensis Hoehne, M. fasciculata Gardn., M. lymanii Wurdack, M. paniculata (DC.) Naud., M. theizans (Bonpl.) Cogn., M. valtheri Naud. Analytical key, descriptions, illustrations, phenology, and geographic distribution of the species are provided.
\end{abstract}

Keywords: Melastomataceae, Survey, Taxonomy

RESUMO - (Miconia Ruiz \& Pav. no Núcleo Curucutu, Parque Estadual da Serra do Mar, Estado de São Paulo, Brasil). Este trabalho consiste no levantamento de Miconia Ruiz e Pav. (Melastomataceae) no Núcleo Curucutu, Parque Estadual da Serra do Mar, Estado de São Paulo, Brasil. Foram registradas nove espécies de Miconia: M. cabucu Hoehne, M. chartacea Triana, M. cinnamomifolia (DC.) Naud., M. cubatanensis Hoehne, M. fasciculata Gardn., M. lymanii Wurdack, M. paniculata (DC.) Naud., M. theizans (Bonpl.) Cogn., M. valtheri Naud. Para o reconhecimento das espécies, são apresentadas chave analítica, descrições, ilustrações, fenologia e distribuição geográfica.

Palavras-chave: Levantamento, Melastomataceae, Taxonomia

\section{Introdução}

A família Melastomataceae apresenta cerca de 170 gêneros e 4.200-4.500 espécies com distribuição pantropical, com aproximadamente 3.000 espécies nos neotrópicos (Martins 2009). No Brasil ocorrem 67 gêneros e 1.325 espécies (Baumgratz et al. 2012), representando uma das principais famílias da flora brasileira (Souza \& Lorenzi 2012) com distribuição desde o Amazonas até o Rio Grande do Sul, presente em praticamente todas as formações vegetais com um número variável de espécies (Romero \& Martins 2002).

Miconia Ruiz \& Pav. é o maior gênero de Melastomataceae com aproximadamente 1.000 espécies com distribuição desde o sul do México até o norte da Argentina e Uruguai. Podemos diferenciar este gênero das demais Melastomataceae pelas folhas destituídas de formicários, inflorescências terminais, pétalas usualmente arredondadas a obtusas no ápice, cálice com lacínias externas reduzidas, frutos bacáceos (Martins et al. 1996, Goldenberg 2009).

O presente trabalho teve por objetivos o estudo taxonômico de espécies de Miconia presentes no Núcleo Curucutu, com coletas, identificações, descrições, ilustrações e dados de distribuição geográfica e fenológicas das espécies encontradas.

\section{Material e métodos}

O Núcleo Curucutu faz parte do Parque Estadual da Serra do Mar (P.E.S.M.) e ocupa parte dos municípios de Itanhaém, Juquitiba, Mongaguá e São Paulo, com uma área de aproximadamente 37.500 ha (S.A.P. 2014), caracteriza-se pela presença de formações campestres e florestais onde estão as nascentes dos rios Embu-Guaçu e Capivari, integrantes do Sistema Guarapiranga e parte do rio Mambu que abastece Itanhaém. Apesar de sua importância e de sua localização nas proximidades da capital paulista,

1. Instituto de Botânica, Av. Miguel Estéfano, 3687, 04101-902 São Paulo, SP, Brasil

2. Universidade de Santo Amaro, Ciências Biológicas, Rua Prof. Enéas de Siqueira Neto, 340, 04829-300 São Paulo, SP, Brasil

3. Autor para correspondência: aderodrigues.bio@ig.com.br 
trata-se ainda de uma porção pouco conhecida da Serra do Mar (Garcia \& Pirani 2005). Com o intuito de contribuir com dados sobre esta área, os herbários PMSP e Unisa desenvolvem em parceria o estudo da flora do Núcleo Curucutu. Várias famílias já foram ou vem sendo estudadas, entre elas Ericaceae (Takeuchi \& Affonso 2009), Gentianaceae (Pscheidt \& Affonso 2008), Iridaceae (Takeuchi et al. 2008), Orchidaceae (Rosa \& Affonso 2009) e Melastomataceae, com o estudo taxonômico dos gêneros Tibouchina Aubl. (Silva \& Affonso 2005) e Leandra Raddi (RodriguesLima \& Affonso 2010).

As espécies tratadas neste trabalho, foram coletadas no setor de planalto do Núcleo Curucutu. A herborização seguiu a metodologia descrita por Fidalgo \& Bononi (1989) e os materiais coletados foram depositados nos Herbários PMSP e Unisa.

Para a obtenção de dados comparativos com as amostras provenientes do Núcleo Curucutu, visitou-se os seguintes herbários: PMSP, SP, SPF e UEC (acrônimos de acordo com Thiers [continuamente atualizado]). Os dados de floração e frutificação foram reunidos por meio das análises das exsicatas e de consultas à literatura. As informações sobre a distribuição geográfica de cada espécie foram obtidas da literatura sobre a família (Martins 2009, Goldenberg \& Caddah 2014).

As análises e as identificações das amostras foram realizadas por comparação das mesmas com a literatura (Martins et al. 1996, 2009, et al. 2009, Goldenberg 2004, 2009, Silva \& Romero 2008, Barberena et al. 2010, Goldenberg \& Caddah 2014) e com as coleções depositadas nos herbários consultados. A terminologia morfológica segue Harris e Harris (1994) e Gonçalves e Lorenzi (2007). Os desenhos foram realizados à mão-livre com o auxílio de um estereomicroscópio para análise das estruturas menores. Utilizou-se material herborizado e/ou fixado em álcool $70 \%$.

\section{Resultados e Discussão}

\section{Miconia Ruiz e Pav.}

Arvoretas ou árvores. Ramos cilíndricos ou quadrangulares, glabros ou pilosos. Folhas opostas, limbo oval, elíptico ou lanceolado; membranáceo, cartáceo ou coriáceo; ápice atenuado, acuminado ou longo acuminado; base arredondada, atenuada, decorrente ou cuneada; margem íntegra, repanda, levemente denticulada, levemente denticulada e revoluta, revoluta ou serrilhada; nervação acródoma basal ou suprabasal; 3-5 nervuras. Inflorescências em panícula simples ou de glomérulos, piramidal ou cilíndrica, terminal; eixo da inflorescência glabro ou piloso. Flores pentâmeras, pediceladas ou sésseis; bractéolas florais involucrais, subuladas, lanceoladas ou estreito-elípticas, caducas ou persistentes. Hipanto glabro ou piloso; cálice caduco ou persistente. Pétalas brancas, ápice arredondado ou cuspidado, oboval, glabras, simétricas. Estames 10-17, glabros, isomorfos ou dimorfos; antera oblonga branca, uniporosa, biporosa ou tetraporosa. Estilete glabro; filiforme ou espessado. Ovário trilocular semi-ínfero, ínfero ou súpero, glabro ou piloso. Fruto baga com muitas sementes por lóculo, tricomas, lacínios e bractéolas persistentes no fruto.

\section{Chave para as espécies de Miconia no Núcleo Curucutu}

\section{Folhas com 5 nervuras}

2. Limbo de 14-29 cm compr., face abaxial com indumento estrelado-lepidoto, ocráceo, nervuras suprabasais .....

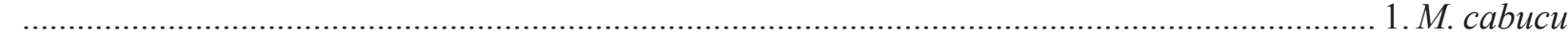

2. Limbo de 10-20 cm compr., face abaxial com indumento estrelado-dendrítico, ferrugíneo, nervuras basais

9. M. valtheri

1. Folhas com 3 nervuras

3. Nervuras basais

4. Limbo glabro

5. Ramos cilíndricos com projeções interpeciolares na região dos nós; anteras uniporosas

3. M. cinnamomifolia

5. Ramos cilíndricos sem projeções interpeciolares na região dos nós; anteras tetraporosas

8. M. theizans

4. Limbo com indumento estrelado-lepidoto

6. Face abaxial com indumento canescente a ocráceo; anteras uniporosas 4. M. cubatanensis

6 . Face abaxial com indumento ferrugíneo; anteras biporosas 6. M. lymani 
3. Nervuras suprabasais

7. Limbo elíptico, nervuras suprabasais posicionadas até $0,3 \mathrm{~cm}$ da base, nervura central unida ao par interno por membrana 7. M. paniculata

7. Limbo lanceolado, nervuras suprabasais posicionadas acima de $0,5 \mathrm{~cm}$ da base, nervura central não unida ao par interno por membrana

8. Folhas adultas com face abaxial com tricomas estrelado-lepidoto, face adaxial cinza enegrecida; cálice caduco 2. M. chartacea

8. Folhas adultas com face abaxial com tricomas estrelado simples e esparso estreladodendrítico, face adaxial acinzentada; cálice persistente 5. M. fasciculata

1. Miconia сариси Hoehne, Ostenia: 299. 1933.

Figura 1g

Árvores 6,0-12,0 m alt. Ramos e pecíolos quadrangulares com tricomas estrelado-lepidotos. Pecíolo 4,0-6,0 cm compr.; limbo elíptico, 14,0-29,0 ×9,0-15,0 cm, cartáceo, base arredondada, ápice atenuado, margem íntegra, face adaxial estrelado-lepidoto, glabrescente, face abaxial estrelado-lepidoto, ocrácea, 5 nervuras suprabasais, par interno partindo a $0,5-1,5 \mathrm{~cm}$ da base, par externo partindo a 0,2-0,5 $\mathrm{cm}$ da base. Panícula de glomérulos, piramidal, 13,0-22,0 × 7,0-10,0 cm, eixo da inflorescência estrelado, brácteas subuladas, esparso estreladas, ca. $1 \mathrm{~mm}$ compr., caducas. Flores sésseis, bractéolas subuladas, estreladofurfuráceas, ca. 0,5 $\mathrm{mm}$ compr., caducas; hipanto 3,5-4,0 × 2,0-2,5 mm, estrelado-lepidoto externo e interno; cálice caduco, lacínias internas, ca. $1 \mathrm{~mm}$ compr., estreladas e externas inconspícuas; pétala 2,8-3,0 $\times 2,0-2,1 \mathrm{~mm}$, ápice arredondado; estames 10 , isomorfos, filete $2,5-2,8 \mathrm{~mm}$ compr., antera $3,0-4,0 \mathrm{~mm}$ compr., uniporosa, conectivo projetado ao longo de toda teca e não prolongado além da antera; ovário glabro, semi-ínfero, estilete levemente espessado no ápice ca. 4,0 $\mathrm{mm}$ compr. Fruto verde a atropurpúreo, 4,0-5,0 × 4,0-5,0 mm.

Material examinado: BRASIL. SÃo PaUlo: Trilha do Mambú, 3-IX-1999, fl., R.J.F. Garcia 1758 (UNISA); Trilha do Mambú, 23-IX-2002, fl., P. Affonso 601 (UNISA); Trilha do Rio Embu, 29-VI-2012, fl., P. Affonso 1284 (UNISA).

Material adicional examinado: BRASIL. São Paulo: Parque Santo Dias, Trilha da Vochysia, 20-XI-1992, fr., R.J.F. Garcia 261 (PMSP). Parque do Carmo, 19-VIII-1982, fl., fr., A. Uryu 21 (PMSP); Parque Guarapiranga, 30-X-1987, fl., G. Hasmito \& S. Honda s.n. (PMSP). Paraná: Paranaguá. Morro do Meio, 25-XII-1986, fl., R.M. Britez s.n. (UEC). Parque Tizo, 21-IX-2007, fl., R.J.F. Garcia 3114 (PMSP). Parque
Natural Municipal da Cratera de Colônia, 8-XI-2007, fl., S.L. Marçon 18 (PMSP).

Miconia cabucu é endêmica do Brasil com ocorrência na Mata Atlântica, presente nos Estados do Rio de Janeiro, São Paulo, Paraná e Santa Catarina. A espécie floresce e frutifica de agosto a dezembro. No Núcleo Curucutu foi coletada em flor nos meses de junho e setembro.

Esta espécie pode ser distinta das demais espécies de Miconia da área de estudo, por seu grande porte e pelo limbo muito desenvolvido, o maior da área.

2. Miconia chartacea Triana, Trans. Linn. Soc. London 28: 119. 1871.

Figura 1a, b, j

Arvoretas 3,5-4,0 m alt. Ramos e pecíolos cilíndricos com tricomas estrelados e estreladolepidotos no ápice. Pecíolo 1,0-2,0 cm compr.; limbo lanceolado, 8,5-15,0 × 1,5-3,0 cm, cartáceo, base atenuada a decorrente, ápice acuminado, margem íntegra, face adaxial das folhas jovens estreladolepidoto, depois glabra e cinza enegrecida, face abaxial estrelado-lepidoto, ocrácea, entremeada por dendríticos esparsos ferrugíneos, 3 nervuras suprabasais partindo a $0,5-0,8 \mathrm{~cm}$ da base, nervura central não unida ao par interno por membrana. Panícula de glomérulos, piramidal, 10,0-17,0 × 8,0-14,0 cm, eixo da inflorescência estrelado-lepidoto, brácteas subuladas ca. 0,6 mm estrelado-lepidotos. Flores sésseis, bractéolas subuladas, estrelado-lepidotos, ca. 0,5 mm compr., caducas; hipanto ca. 3,0 $\times 3,0 \mathrm{~mm}$, estrelado externo e interno; cálice caduco, lacínias internas triangulares, ca. $1 \mathrm{~mm}$ compr., e lacínias externas formados por dentículos agudos; pétala, ca. 2,0 $\times 1,5 \mathrm{~mm}$, ápice arredondado; estames 10 , isomorfos, filete ca. 3,0 mm compr., antera ca. 2,0 mm compr., uniporosa, conectivo projetado ao longo de toda teca e não prolongado alem da antera; ovário glabro, ínfero, estilete levemente espessado no ápice ca. 5,0 mm compr. Fruto, verde (fruto maduro não observado), ca. 3,0 × 4,0-5,0 mm. 


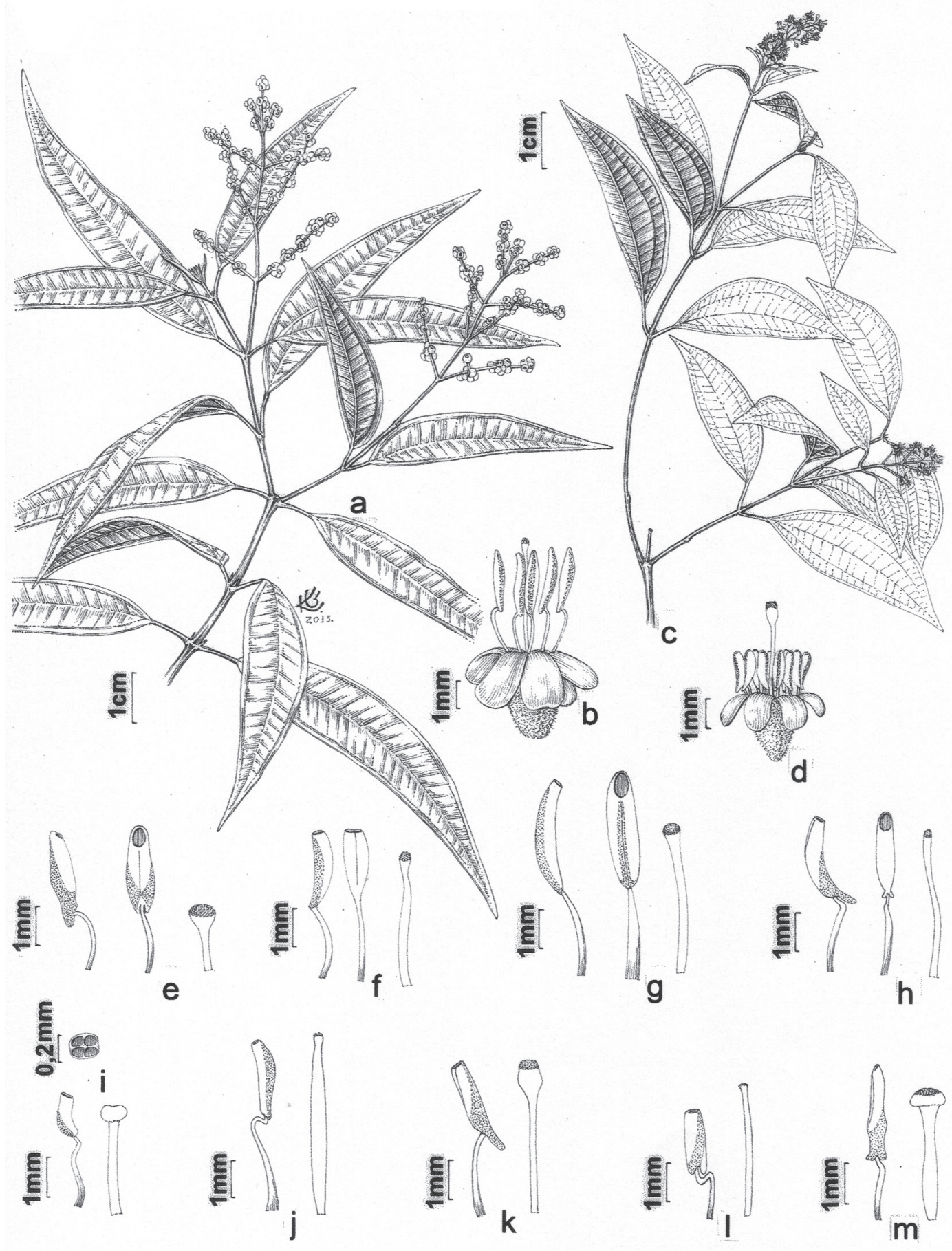

Figura 1. a-b. Miconia chartacea. a. Porção de um ramo com frutos. b. Flor. c-d. M. paniculata. c. Porção de um ramo com flores. d. Flor. e-h. Estames em vista lateral e ventral e estiletes. e. M. cinnamomifolia. f. M. fasciculata. g. M. cabucu. h. M. cubatanensis. i. M. theizans - estame em vista lateral, com detalhe da antera tetraporosa $\mathrm{e}$ estilete. j-m. Estames em vista lateral e estiletes. j. M. chartacea. k. M. paniculata. 1. M. lymanii. m. M. valtheri.

Figura 1. a-b. Miconia chartacea. a. Portion of a branch with fruit. b. Flower. c-d. M. paniculata. c. Portion of a branch with flower. d. Flower. e-h. Stamens in lateral and ventral view and styles. e. M. cinnamomifolia. f. M. fasciculata. g. M. cabucu. h. M. cubatanensis. i. M. theizans - stamen in side view, with detail of tetraporate anther and styles. j-m. Stamens in side view and styles. j. M. chartacea. k. M. paniculata. 1. M. lymanii. m. M. valtheri. 
Material examinado: BRASIL. S̃̃o PAULO: Trilha do Mirante, 21-XII-2009, fl., P. Affonso 1187 (UNISA); Trilha do Mirante, 17-III-2010, fr., P. Affonso 1209 (UNISA); Trilha do Mirante, 20-IV-2011, fr., $P$. Affonso 1253 (UNISA).

Espécie endêmica do Brasil, ocorrendo em formações florestais, cerrados e caatinga desde a Bahia, Goiás, Distrito Federal, Minas Gerais, Espírito Santo até Santa Catarina. A espécie floresce de outubro a dezembro, e frutifica de março a maio. Coletada com flores em dezembro e com frutos em março e abril.

Algumas espécies apresentam muita semelhança com M. chartaceae, Martins et al. (1996) citam a proximidade com M. brunnea DC., que se diferencia por apresentar folhas maiores, com base totalmente decurrente no pecíolo e as nervuras que divergem a $7 \mathrm{~cm}$ acima da base, em M. chartaceae esta distância não ultrapassa 1,5 cm. Barberena et al. (2010) apontam a semelhança com $M$. budlejoides Triana que se diferencia por apresentar ovário piloso e o apêndice bilobado. Goldenberg (2009) também cita M. brunnea além de $M$. willdenowii Naudin e $M$. flammea Casar., para este autor os limites entre estas espécies não está claro, sugerindo a necessidade de uma revisão para todo o grupo de espécies com inflorescências glomeruladas da seção Glossocentrum (Crueger) Hook.

3. Miconia cinnamomifolia (DC.) Naudin, Ann. Sci.

Nat. Bot., sér. 3, 16: 168. 1850. Figura 1e

Arvoretas 2,0-2,5 m alt. Ramos cilíndricos com projeções interpeciolares na região dos nós, com tricomas estrelados no ápice, após glabro. Pecíolos cilíndricos, 0,5-0,8 cm compr.; limbo oval a elíptico, 3,7-5,0 × 1,5-2,0 cm, membranáceo a cartáceo, base cuneada, ápice atenuado, margem repanda, face adaxial e abaxial glabras, estrelado nas folhas jovens, face abaxial olivácea, 3 nervuras basais. Panícula piramidal, 3,5-4,0 × 2,0-3,0 cm, eixo da inflorescência esparso estrelado, brácteas ausentes. Flores com pedicelos ca. $1 \mathrm{~mm}$ compr., bractéolas lanceoladas, estreladas, ca. 0,5 mm compr., caducas; hipanto 1,0-2,0 × ca. $1 \mathrm{~mm}$, glabro; cálice caduco, internas arredondadas a triangulares, ca. $1 \mathrm{~mm}$ compr. e lacínias externas inconspícuas, estreladas; pétala, 1,1-1,5 × 1,0-1,2 mm, ápice arredondado; estames 10, dimorfos, filete 1,2-1,5 mm compr., antera 1,6-1,8 mm compr., uniporosa, conectivo projetado na base da teca e prolongado ca. $0,5 \mathrm{~mm}$ além da antera; ovário, glabro, semi-ínfero, estilete filiforme, ca. 1,3 mm compr., abruptamente espessado no ápice. Fruto verde acinzentado a atrovioláceo, 2,0-3,0 × 2,0-3,0 mm.

Material examinado: BRASIL. SÃo PAULO: Trilha da Entrada, 16-XII-2004, fl., P. Affonso 756 (UNISA). Trilha da Entrada, 24-II-2010, fr., P. Affonso 1193 (UNISA). Trilha da Entrada, 24-II-2010, fr., P. Affonso 1196 (UNISA); Trilha da Entrada, 20-IV-2011, fr., $P$. Affonso $1239 b$ (UNISA).

Material adicional examinado: BRASIL. MINAS GeraIs: Itabirito, 12-XII-1970, fl., P. Leopoldo 9685 (SP). Camundacaia, 25-II-1976, fl., W.G.D. Arcy 10.564 (SP). Carrancas, Trilha da Cachoeira da Fumaça, 9-XII-1983, fl., A.M.A. Tozzi 15.407 (SP). Belo Horizonte, 19-XI-1982, fl., M. Barreto 6645 (SP). Rodovia Datas, Serra Morro do Coco, 8-I-1988, fl., V. Meguro s.n. (SPF).

Espécie endêmica do Brasil, ocorrendo nas formações florestais da Mata Atlântica desde a Bahia até Santa Catarina. Floresce entre novembro e janeiro, coletada com flor também em julho e frutifica entre dezembro e agosto. Na área de estudo floresceu no mês de dezembro e foi coletada com frutos em fevereiro e abril.

Esta espécie pode ser facilmente identificada pela presença das projeções interpeciolares nos ramos na região dos nós. Martins et al. (1996), associou a esta característica o elevado porte da espécie, comparável, em São Paulo, com o de M. cabucu. No Núcleo Curucutu encontramos apenas indivíduos de porte reduzido, outros autores também relataram portes menores como arbustivo (Goldenberg 2004) e arvoreta (Barberena et al. 2010).

4. Miconia cubatanensis Hoehne, Anexos Mem. Inst.

Butantan, Secç. Bot 1(5): 139. 1922.

Figura $1 \mathrm{~h}$

Árvores 2,0-5,0 m alt. Ramos e pecíolos cilíndricos com tricomas estrelado-lepidotos no ápice. Pecíolo 0,6-2,0 cm compr.; limbo lanceolado, 5,0-9,0 × 2,0-3,1 cm, cartáceo, base cuneada, ápice longo-acuminado, margem íntegra, face adaxial estrelado-lepidoto, glabrescente, face abaxial densamente estrelado-lepidoto, canescente a ocrácea, 3 nervuras basais. Panícula cilíndrica, 2,0-4,5 × 7,0-10,0 cm, eixo da inflorescência estrelado, brácteas deltóides, esparso estreladas, ca. $0,5 \mathrm{~mm}$ compr., caducas. Flores com pedicelos ca. $1 \mathrm{~mm}$ compr., bractéolas estreito-elípticas, estrelado- 
furfuráceas, ca. 0,5 $\mathrm{mm}$ compr., caducas; hipanto 1,0-1,8 $\times$ ca. 2,0 mm, estrelado-lepidotos externo e interno; cálice caduco, lacínias internas triangulares ca. $1 \mathrm{~mm}$ compr., estrelado-lepidotos, externas inconspícuas; pétala 2,8-3,0 × 2,0-2,1 mm, ápice cuspidado; estames 10, isomorfos, filete $2,5-2,8 \mathrm{~mm}$ compr., antera oblonga, branca, 2,1-2,3 mm compr., uniporosa, conectivo projetado no dorso e prolongado ca. $0,5 \mathrm{~mm}$ além da antera; ovário estrelado, semiínfero, estilete filiforme não espessado no ápice, ca. 4,0 mm compr. Fruto atropurpúreo, 3,0-4,0 × 3,0$6,0 \mathrm{~mm}$.

Material examinado: BRASIL. São Paulo: Trilha da Entrada, 3-IV-1998, fr., P. Affonso 259 (UNISA). Trilha da Entrada, 15-V-1998, fl., L.C.Q.M.P. Sampaio 97 (UNISA). Trilha do Mirante, 28-V-1999, fl., F. Morrone 2 (UNISA). Trilha da Cachoeira do Banquinho, 30-VI-1999, fl., P. Affonso 405 (UNISA). Trilha do Mirante, 14-VI-2004, fl., P. Affonso 660 (UNISA). Trilha do Mirante, 14-VI-2004, fl., P. Affonso 661 (UNISA). Trilha da Cachoeira do Banquinho, 14-VI-2004, fl., fr., P. Affonso 662 (UNISA). Trilha do Mirante, 22-IX-2004, fr., P. Affonso 707 (UNISA). Trilha do Mirante, 9-VI-2005, fr., P. Affonso 832 (UNISA). Trilha do Mirante, 15-V-2010, fr., P. Affonso 1230 (UNISA); Trilha do Mirante, 20-IV-2011, fl., P. Affonso 1245 (UNISA). Trilha do Mirante, 20-IV-2011, fl., P. Affonso, 1247 (UNISA).

Material adicional examinado: BRASIL. BRAsíliA: Distrito Federal. Reserva Ecológica do IBGE, 22-VIII-1989, fl., M.A. Silva \& E.C. Lopes s.n. (SP). Distrito Federal, 2-VII-1988, fl., J.E. Paula 3144 (SP). Golás: Alvorada do Norte, 20-X-1995, fl., B.A.S. Pereira \& D. Alvarenga 2917 (SP). Minas Gerais: São Roque de Minas. Trilha da Cachoeira Casca D'Anta, 24-V-1996, fl., fr., R. Romero \& J.N. Nakajima 3451 (SP). Araxá, VI-1989, fl., Shiguenori Kajiva s.n. (SP). São PAULO: Parque Santo Dias, Trilha da administração, 25-VII-1993, fl., R.J.F. Garcia 404 (PMSP). Parque Santo Dias, Trilha Principal, 28-VII1992, fl., R.J.F. Garcia 127 (PMSP). Parque Municipal Alfredo Volpi, 30-X-1994, fl., S. Aragaki 582 (PMSP).

Espécie endêmica do Brasil, ocorrendo no Cerrado e na Mata Atlântica, presente nos Estados do Mato Grosso e da Bahia até Santa Catarina e no Distrito Federal, com flores entre fevereiro e julho e com frutos entre abril e outubro. $\mathrm{Na}$ área de estudo floresceu de abril a junho e frutificou de abril a junho e em setembro.
É facilmente diferenciada das demais espécies presentes na área, por suas folhas curtas, cartáceas e longamente acuminadas no ápice, com indumento ocráceo a canescente na face abaxial.

5. Miconia fasciculata Gardner, London J. Bot. 1: 533. 1842.

Figura 1f

Árvores 2,0-3,0 m alt. Ramos e pecíolos cilíndricos com tricomas estrelados e dendríticos mais densos em direção ao ápice. Pecíolo 0,7-2,0 cm compr.; limbo lanceolado, 13,0-22,0 × 2,5-4,5 cm, cartáceo, base cuneada, ápice acuminado, margem levemente denticulada, face adaxial estrelado, glabrescente, acinzentada, face abaxial estrelado simples e esparso estrelado dendrítico, ocrácea, 3 nervuras suprabasais partindo a $0,5-1,0 \mathrm{~cm}$ da base, nervura central não unida ao par interno por membrana. Panícula de glomérulos, piramidal, 5,0-10,0 × 3,0-6,0 cm, eixo da inflorescência estrelado, brácteas estreitoelípticas, estreladas, 0,5-2,0 $\mathrm{mm}$ compr., caducas. Flores sésseis, bractéolas estreito-elípticas, estreladofurfuráceas, ca. 0,5 mm compr., persistentes; hipanto ca. 3,0 × 2,0 mm, estrelado furfuráceo externo e interno; cálice persistente, lacínias internas ca. $0,9 \mathrm{~mm}$ compr. e externas ca. $0,5 \mathrm{~mm}$ compr., ambas triangulares e estreladas; pétala, ca. 3,0 × 1,2 $\mathrm{mm}$, ápice cuspidado; estames 10 , isomorfos, filete ca. $2 \mathrm{~mm}$ compr., antera ca. 2,0 mm compr., uniporosa, conectivo projetado no dorso e prolongado ca. $0,5 \mathrm{~mm}$ além da antera; ovário estrelado, súpero, estilete filiforme não espessado no ápice, ca. 3,5 mm compr. Fruto verde (fruto maduro não observado), ca. 3,0 × 2,0-3,0 mm.

Material examinado: BRASIL. S̃̃o PAUlo Trilha da Cachoeira do Banquinho, 13-XII-1997, fl., R.J.F. Garcia 1428 (UNISA). Trilha do Banquinho, 21-XII-1999, fl., P. Affonso 437 (UNISA). Trilha do Mirante, 28-IV-2000, fr., M.A.S. Mayworm 165 (UNISA). Trilha do Mirante, 16-XII-2004, fl., P. Affonso 769 (UNISA); Trilha da Captação de Água, 22-XII-2005, fl., P. Affonso 895 (UNISA); Trilha do Mirante, 21-XII-2009, fl., P. Affonso 1185 (UNISA); Trilha do Mirante, 17-III-2010, fr., P. Affonso 1204 (UNISA).

Material adicional examinado: BRASIL. São PAULO: Cubatão, 21-XI-1998, fl., W. Ribeiro s.n. (SP). Biritiba Mirim, Estação Biológica de Boracéia, s.d., fl., A.C. Filho 2131 (SP). Ilhabela, 15-III-1990, fl., fr., M.J. Robim 650 (SPF). Ubatuba, s.d, fl., F. Barros 2849 (SP). Parque Municipal Alfredo Volpi, 6-V-1994, fl., S. Aragaki 583 (PMSP). 
Espécie endêmica do Brasil, presente da Bahia até Santa Catarina em formações florestais litorâneas e sobre a Serra do Mar. Floresce entre outubro e dezembro e frutifica entre dezembro e junho. Na área de estudo floresceu em dezembro e frutificou em março e abril.

M. fasciculata é confundida com M. racemifera (DC.) Triana que se difere da primeira por apresentar tricomas com ramos mais longos, cálice com lacínias externas mais longas e agudas, estames maiores e inflorescência com glomérulos mais contraídos (Goldenberg 2004, 2009). Dentre as espécies presentes na área difere das demais por seu limbo longo lanceolado com face adaxial enegrecida.

6. Miconia lymanii Wurdack, Sellowia 14: 164. 1962. Figura 11

Arvoretas 1,0-2,5 m alt. Ramos e pecíolos cilíndricos com tricomas estrelados mais densos em direção ao ápice. Pecíolo 0,4-2,5 cm compr.; limbo elíptico, 4,0-12,5 × 1,5-5,5 cm, coriáceo, base cuneada, ápice acuminado, margem levemente denticulada e revoluta, face adaxial estreladofurfurácea, glabrescente, face abaxial estreladolepidoto, ferrugínea, 3 nervuras basais. Panícula de glomérulos, piramidal, 6,0-9,0 ×4,0-7,0 cm, eixo da inflorescência estrelado, brácteas ausentes. Flores sésseis, bractéolas estreito-elípticas, estreladofurfuráceas, interno glabras, ca. 0,5 $\mathrm{mm}$ compr., persistentes; hipanto ca. 3,0 $\times 3,0 \mathrm{~mm}$, estrelado furfuráceo externo, interno glabro; cálice caduco, lacínias internas ca. 1,1 mm compr. e externas ca. $0,5 \mathrm{~mm}$ compr., ambas triangulares e estreladas; pétala, ca. 2,0 × 1,0 mm, ápice cuspidado; estames 10 , isomorfos, filete ca. 2,0 $\mathrm{mm}$ compr., antera ca. 2,0 mm compr., biporosa, conectivo projetado no dorso e prolongado ca. $0,5 \mathrm{~mm}$ além da antera; ovário estrelado, semi-ínfero, estilete filiforme, não espessado no ápice, ca. $3,5 \mathrm{~mm}$ compr. Fruto vermelho a atrovioláceo, 3,0-4,0 × 2,0-4,0 mm.

Material examinado: BRASIL. SÃo PAULO: Trilha do Campo, 18-I-1996, fr., S.J. Sordi et al. 919 (PMSP). Trilha do Campo, 18-XII-1996, fl., R.J.F. Garcia 932 (UNISA). Trilha do Campo, 13-II-1997, fr., R.J.F. Garcia et al. 1038 (UNISA). Trilha do Rio Embu-Guaçú, 14-II-1997, fr., R.J.F. Garcia 1072 (UNISA). Trilha do Campo, 15-XI-1997, fl., R.J.F. Garcia 1376 (UNISA). Trilha do Mirante, 7-XI-1998, fr., P. Affonso 211 (UNISA). Trilha do Mirante, 16-XII-2004, fl., P. Affonso 766 (UNISA). Trilha do Mirante, 17-III-2010, fr., P. Affonso 1206 (UNISA).
Material adicional examinado: BRASIL. PARANÁ. Guaratuba, Serra do Aroçatuba, 8-IV-2000, fl., O.S. Ribos 418 (SPF). Serra da Papanduva, 4-XII-2003, fl., J.M. Silva 802 (SPF).

Espécie endêmica do Brasil, presente nos Estados do Rio de Janeiro, São Paulo, Paraná e Santa Catarina, na Mata Atlântica, em vegetação aberta ou floresta de altitudes elevadas. Floresce em novembro e dezembro e frutifica entre janeiro e junho. $\mathrm{Na}$ área de estudo floresceu em novembro e dezembro e frutificou em novembro e entre janeiro e março.

Miconia lymanii pode ser confundida com M. hyemalis A.St.-Hil. \& Naudin, que geralmente tem folhas com superfície tendendo à bulada e nervuras transversais em número menor 10-20 e com espaçamento maior do que as folhas de $M$. lymanii (25-30 nervuras transversais), os tricomas da face abaxial nesta espécie são estrelados lepidotos, às vezes também com dendríticos que podem cobrir os estrelados lepidotos, enquanto em $M$. hyemalis os tricomas são estrelados estipitados, com ramos muito mais longos do que na primeira (Goldenberg 2004, 2009).

7. Miconia paniculata (DC.) Naudin, Ann. Sci. Nat. Bot., sér. 3, 16: 245. 1850.

Figura 1c, d, k

Árvores ca. 3 m alt. Ramos e pecíolos cilíndricos com tricomas estrelado-furfuráceos em direção ao ápice. Pecíolo 0,5-1,0 cm compr.; limbo elíptico, 4,5-10,0 × 1,8-3,0 cm, membranáceo, base cuneada, ápice longo-acuminado, margem inteira ou repanda, faces adaxial e abaxial estrelado, glabrescente, olivácea, 3 nervuras suprabasais partindo a $0,1-0,3 \mathrm{~cm}$ da base, unidas na base por membrana, nervura central unida ao par interno por membrana. Panícula piramidal, 3,5-6,0 × 2,0-6,5 cm, eixo da inflorescência estrelado, brácteas subuladas, esparso estreladas, ca. $3 \mathrm{~mm}$ compr., caducas. Flores com pedicelos 2,0-3,0 mm compr., bractéolas subuladas, esparso estreladas, ca. 2,0 mm compr., caducas; hipanto ca. 2,0 $\times 2,0 \mathrm{~mm}$, estrelado furfuráceo; cálice caduco, lacínias internas triangulares, ca. 1,0 mm compr., glabras e externas triangulares ca. 1,0 mm compr., estrelada; pétala ca. $2,1 \times 1,2 \mathrm{~mm}$, ápice arredondado; estames 13-18, isomorfos, filete ca. 2,0 mm compr., antera ca. 2,0 mm compr., uniporosa, conectivo projetado ao longo de toda teca e prolongado ca. 0,5 $\mathrm{mm}$ além da antera; ovário glabro, ínfero, estilete filiforme espessado no ápice, ca. $4 \mathrm{~mm}$ compr. Fruto atropurpúreo, 2,0-3,0 × ca. 2,0 mm. 
Material examinado: BRASIL. São PAULO: Trilha do Mirante, 11-XII-2006, fl., P. Affonso 958 (UNISA). Trilha do Mirante, 17-III-2010, fr., P. Affonso 1203 (UNISA).

Espécie endêmica do Brasil, ocorrendo na Mata Atlântica e Cerrado, presente nos Estados da Bahia, Espírito Santo, Minas Gerais, Rio de Janeiro, São Paulo, Paraná e Santa Catarina. Floresce em novembro e dezembro e frutifica em janeiro e julho. Na área de estudo foi coletada com flor em dezembro e fruto em março.

Miconia paniculata era muito confundida com M. doriana Cogn. e M. depauperata Gardner, a diferenciação entre estas espécies era baseada no número de estames e de bractéolas. Goldenberg \& Caddah (2014) reconheceram-nas como sinônimos de M. paniculata.

8. Miconia theizans (Bonpl.) Cogn. in Mart., Eichler \& Urb., Fl. bras. 14(4): 419. 1888.

Figura $1 \mathrm{i}$

Árvores 2,5-8,0 m alt. Ramos e pecíolos cilíndricos glabros. Pecíolo 0,5-2,1 cm compr., limbo elíptico, 5,1-14,3 × 1,7-4,5 cm, membranáceo, base cuneada, ápice longo-acuminado, margem levemente revoluta e serrilhada, faces adaxial e abaxial glabras, verde claro, 3 nervuras basais. Panícula piramidal, 4,3-12,1 × 3,0-11,3 cm, eixo da inflorescência glabro, brácteas estreito-elípticas, glabras, ca. 2,0 mm compr., caducas. Flores com pedicelos ca. 1,0 $\mathrm{mm}$ compr., bractéolas estreitoelípticas, glabras, ca. $0,5 \mathrm{~mm}$ compr., persistentes; hipanto $1,0-1,5 \times 1,0-1,2 \mathrm{~mm}$, glabro; cálice persistente, lacínias internas arredondadas, ca. $0,5 \mathrm{~mm}$ compr., glabras e externas triangulares, ca. $0,2 \mathrm{~mm}$ compr., glabras; pétala ca. 1,0 × 1,0 mm, ápice cuspidado; estames 10, isomorfos, filete ca. 2,0 mm compr., antera ca. 1,0 $\mathrm{mm}$ compr., tetraporosa, conectivo projetado no ventre e não prolongado além da antera; ovário glabro, semi-ínfero, estilete filiforme espessado no ápice ca. $3 \mathrm{~mm}$ compr. Fruto verde a atropurpúreo, 1,5-2,0 × 2,0-2,2 mm.

Material examinado: BRASIL. SÃo PAulo: Trilha da Entrada, 21-XII-1999, fl., P. Affonso 441 (UNISA). Trilha da Casa Abandonada, 23-XI-2000, fl., M.A.S. Mayworm 195 (UNISA). Trilha Nova do Mirante, 21-XII-2000, fl., P. Affonso 478 (UNISA). Trilha do Banquinho, 27-IV-2001, fl., fr., M.A.S. Mayworm 207 (UNISA). Trilha do Mirante, 16-XII-2004, fl., P. Affonso 782 (UNISA). Trilha do Mirante,
16-XII-2004, fl., P. Affonso 784 (UNISA). Trilha da Entrada, 8-XII-2005, fl., P. Affonso 878 (UNISA). Trilha da Entrada, 21-XII-2009, fl., fr., P. Affonso 1180 (UNISA). Trilha do Lago, 21-XII-2009, fl., fr., $P$. Affonso 1190 (UNISA). Trilha do Lago, 21-XII-2009, fl., fr., P. Affonso 1191 (UNISA); Heliponto, 15-V-2010, fl., fr., P. Affonso 1226 (UNISA). Trilha do Mirante, 20-IV-2011, fr., P. Affonso 1243 (UNISA).

Material adicionado examinado: BRASIL. BRASílIA: Distrito Federal. Reserva Ecológica do IBGE, 31-I-1985, fl., R.C. Mendonça 426 (SP). Minas Gerais: Serra do Araponga, Fazenda Neblina, 1-II-1992, fr., L.S. Leoni 1748 (SP). Santo Antônio do Itambé, 12-III-1995, fl., J.P. Souza 8413 (SP). Paraná: Palmeira, Rio dos Paragaios, 11-II-1988, fl., O. Ribas 679 (SP). São Paulo: Biritiba Mirim, Estação Biológica de Boracéia, 29-V-1986, fl., A.C. Filho 2639 (PMSP). Parelheiros, Fazenda da SABESP, 13-II-1995, fl., R.J.F. Garcia 521 (PMSP). São Paulo, Parque Ecológico do APA do Carmo, Trilha 1, 25-V-2004, fl., fr., R.J.F. Garcia 496 (PMSP).

Espécie não endêmica do Brasil, com ampla distribuição no Neotrópico, ocorrendo do sul do México até o Paraguai. No Brasil é encontrada nos Estados de Goiás e da Bahia até Santa Catarina e no Distrito Federal, nos domínios Cerrado e Mata Atlântica, geralmente em áreas brejosas e florestas ciliares. Coletada com flores e frutos praticamente o ano todo. Na área de estudo os exemplares foram encontrados com flor nos meses de abril e maio e novembro e dezembro, e em fruto nos meses de abril e maio e dezembro.

Miconia theizans é extremamente semelhante a $M$. hirtella Cogn., a distinção se dá pela presença de tricomas simples nas folhas e, às vezes, ramos de M. hirtella. Para Martins et al. (2009) a presença ou ausência dos tricomas possa ser mera variação morfológica, tratando-se de uma única espécie. No Núcleo Curucutu, M. theizans distingue-se facilmente das demais por ser a única na área de estudo, a apresentar a antera tetraporada. Esta espécie também apresenta ramo e limbo glabros, características pouco comuns para as espécies da área.

9. Miconia valtheri Naudin, Ann. Sci. Nat. Bot., sér. 3, 16: 155.1850

Figura $1 \mathrm{~m}$

Árvores ca. 6,0 m alt. Ramos quadrangulares com tricomas estrelados e dendríticos. Pecíolo cilíndrico 0,5-1,0 cm compr., com tricomas estrelados 
e dendríticos; limbo elíptico, 10,0-20,0 × 4,0-7,5 cm, cartáceo, base cuneada, ápice acuminado, margem serrilhada na porção superior, face adaxial estrelada e dendrítica, glabrescente, e face abaxial estrelada e dendrítica, ferrugínea, 5 nervuras basais. Panícula de glomérulos, cilíndrica, 6,0-8,0 × 3,0-4,0 cm, eixo da inflorescência estrelado estipitado, brácteas subuladas, estrelados e dendríticos, ca. 2,0 mm compr., caducas. Flores com pedicelos ca. 1,0 mm compr., bractéolas subuladas, estreladas e dendríticas, ca. 2,0 mm compr., caducas; hipanto 3,0-3,2 × 2,5-2,7 mm, estrelado e dendrítico; cálice persistente, lacínias internas triangulares, ca. $0,5 \mathrm{~mm}$ compr., estrelados e dendríticos e lacínias externas triangulares, ca. $0,2 \mathrm{~mm}$ compr., glabras; pétala 1,6-1,8 × 2,4-2,6 mm, ápice cuspidado; estames levemente dimorfos 14-17, filete 1,5-1,7 mm compr., antera 2,0-2,5 mm compr., uniporosa, conectivo projetado abaixo ca. $0,8 \mathrm{~mm}$ de toda antera; ovário glabro, semi-ínfero, estilete abruptamente alargado no ápice ca. $3,5 \mathrm{~mm}$. Fruto verde a atropurpúreo, 1,5-2,0 × 2,0-2,2 mm.

Material examinado: BRASIL. São PAULO: Trilha do Rio Mambú, 17-III-2000, fl., fr., R.J.F. Garcia 1945 (PMSP).

Material adicional examinado: BRASIL. São PAulo: Parelheiros, Centro Paulus, 20-IV-1995, fr., R.J.F.Garcia 661 (PMSP). Parelheiros, Centro Paulus, 20-IV-1995, fr., S.A.P. Godoy et al. 504 (PMSP). Cotia, Cemucam, 6-VIII-2002, fl., $M$. Ortega s.n. (PMSP-5110). Parque Santo Dias, Trilha Principal, 8-III-1993, fr., R.J.F. Garcia 363 (PMSP). Parelheiros, Centro Paulus, 20-IV-1995,fr., R.J.F. Garcia 661 (PMSP).

Miconia valtheri é endêmica do Brasil, presente nos Estados de Minas Gerais, Rio de Janeiro, São Paulo, Paraná e Santa Catarina, em áreas de floresta. Floresce de dezembro a abril e agosto e frutifica de março a abril. $\mathrm{Na}$ área de estudo, foi coletada com flores e frutos no mês de março.

M. valtheri é semelhante a M. eichleri Cogn., da qual difere pela presença de 5 nervuras, enquanto M. eichleri apresenta apenas 3 nervuras. $\mathrm{Na}$ área de estudo diferencia-se facilmente das demais espécies pela presença das 5 nervuras basais e da face abaxial do limbo ferrugíneo. Compartilha com M. cabucu a presença de ramos quadrangulares, mas diferencia-se desta por várias características, entre elas, o limbo menor, recoberto por tricomas estrelados estipitados e 5 nervuras basais.

\section{Agradecimentos}

A equipe do Núcleo Curucutu pelo apoio em todas as nossas coletas. Ao Instituto Florestal pela autorização para realização deste trabalho. Aos Curadores dos herbários visitados, PMSP, SP, SPF e UEC. À Universidade de Santo Amaro pelo apoio financeiro.

\section{Literatura citada}

Affonso, P., Takeuchi, C. \& Nakano, R.K. 2014. Levantamento de Gesneriaceae Rich. \& Juss. no Núcleo Curucutu, Parque Estadual da Serra do Mar, São Paulo, SP, Brasil. Hoehnea, 41: 563-572.

Barberena, F.F.V.A., Chiavegatto, B. \& Baumgratz, J.F. 2010. Melastomataceae nos remanescentes florestais do Parque Estadual do Ibitipoca. Minas Gerais, Brasil. Boletim de Botânica da Universidade de São Paulo, v. 28, n. 2, pp. 141-157.

Baumgratz, J.F.A., Caddah, M.K., Chiavegatto, B., Goldenberg, R., Guimarães, P.J.F., Koschnitzke, C., Kriebel, R., Lima, L.F.G., Martins, A.B., Michelangeli, F.A., Reginato, M., Rocha, M.J.R., Rodrigues, K.F., Romero, R., Rosa, P., SilvaGonçalves, K.C., Souza, M.L.D.R., Woodgyer, E. 2012. Melastomataceae. In: Lista de Espécies da Flora do Brasil. Jardim Botânico do Rio de Janeiro. 2012. Disponível em http://floradobrasil.jbrj.gov.br/2012/ FB000161 (acesso em 15-I-2013)

Fidalgo, O. \& Bononi, V.L.R. 1989. Técnicas de coleta, preservação e herborização de material botânico. São Paulo: Instituto de Botânica.

Garcia, R.J.F. \& Pirani, J.R. 2005. Análise florística. ecológica e fitogeográfica do Núcleo Curucutu, Parque Estadual da Serra do Mar (São Paulo, SP), com ênfase nos campos junto à crista da Serra do Mar. Hoehnea, v. 32, n. 1, pp. 1-48.

Goldenberg, R. 2004. O gênero Miconia (Melastomataceae) no Estado do Paraná, Brasil. Acta Botanica Brasilica, v. 18 , n. 4 , pp. 927-947.

Goldenberg, R. 2009. Miconia Ruiz \& Pav. In: M.G.L. Wanderley, G.J. Shepherd, T.S. Melhem, A.M. Giulietti, S.E. Martins (eds.). Flora Fanerogâmica do Estado de São Paulo. FAPESP, São Paulo, v. 6, pp. 73-103.

Goldenberg, R. \& Caddah, M.K. 2014. Miconia. In: Lista de Espécies da Flora do Brasil. Jardim Botânico do Rio de Janeiro. 2014. Disponível em http://floradobrasil. jbrj.gov.br/jabot/floradobrasil/FB9666 (acesso em 10-X-2014).

Gonçalves, E.G. \& Lorenzi, H. 2007. Morfologia Vegetal: Organografia e Dicionário Ilustrado de Morfologia de Plantas Vasculares. Instituto Plantarum, Nova Odessa. 
Harris, J.G. \& Harris, M.W. 1994. Plant identification terminology: an illustrated glossary. Spring Lake Publishing, Utah.

Martins, A.B. 2009. Melastomataceae In: M.G.L. Wanderley, G.J. Shepherd, T.S. Melhem, A.M. Giulietti, S.E. Martins (eds.). Flora Fanerogâmica do Estado de São Paulo. FAPESP, São Paulo, v. 6, pp. 1-103.

Martins, A.B., Goldenberg, R. \& Semir, J. 2009. Flora de Grão-Mogol, Minas Gerais: Melastomataceae. Boletim de Botânica da Universidade de São Paulo, v. 27, n. 1, pp. 73-96.

Martins, A.B.; Semir, J.; Goldenberg, R.; Martins, E. 2014. O gênero Miconia Ruiz \& Pav. (Melastomataceae) no Estado de São Paulo. Acta Botanica Brasilica, v. 10, n. 2, pp. 267-316.

Pscheidt, A.C. \& Affonso, P. 2008. Levantamento de Gentianaceae Juss. no Núcleo Curucutu, Parque Estadual da Serra do Mar, São Paulo. Revista do Instituto Florestal, 20: 147-153.

Rodrigues-Lima, A.A. \& Affonso, P. 2010. Levantamento de Leandra Raddi no Núcleo Curucutu, Parque Estadual da Serra do Mar, São Paulo. Revista do Instituto Florestal, v. 22, n. 1, pp. 15-32.

Romero, R. \& Martins, A. 2002. Melastomataceae do Parque Nacional da Serra da Canastra, Minas Gerais, Brasil. Revista Brasileira de Botânica, v. 25, n. 1, pp. 19-24.
Rosa, D.A. \& Affonso, P. 2009. Levantamento do gênero Oncidium Sw. Sensu Lato (Orchidaceae) no Núcleo Curucutu, Parque Estadual da Serra do Mar, São Paulo. Revista do Instituto Florestal, 21: 55-62.

Silva, C.V. \& Affonso, P. 2005. Levantamento de Tibouchina Aubl. (Melastomataceae) no Parque Estadual da Serra do Mar, Núcleo Curucutu, São Paulo. Revista do Instituto Florestal, v. 17, n. 2, pp. 195-206.

Silva, M.A.O. \& Romero, R. 2008. Melastomataceae das serras do município de Delfinópolis, Minas Gerais, Brasil. Rodriguésia, v. 59, n. 4, pp. 609-647.

Sistema Ambiental Paulista - S.A.P. 2014. Parque Estadual da Serra do Mar - Núcleo Curucutu. Disponível em http://www.ambiente.sp.gov.br/parque-serra-domar-nucleo-curucutu/ (acesso em12-X-2014).

Souza, V.C. \& Lorenzi, H. 2012. Botânica Sistemática: guia ilustrado para identificação das famílias de Fanerógamas nativas e exóticas no Brasil, baseado em APG III. 3 ed. Instituto Plantarum, Nova Odessa.

Takeuchi, C. \& Affonso, P. 2009. Levantamento de Ericaceae Juss. no Núcleo Curucutu, Parque Estadual da Serra do Mar, São Paulo. Revista do Instituto Florestal, 21: 131-138.

Takeuchi, C., Affonso, P. \& Chukr, N.S. 2008. Levantamento de Iridaceae Juss. no Núcleo Curucutu, Parque Estadual da Serra do Mar, São Paulo. Revista do Instituto Florestal, 20: 51-63.

Thiers, B. 2012. Index herbariorum: A global directoy of public herbaria and associated staff. New York Botanical Garden's Virtual Herbarium. Disponível em http:// sweetgum.nybg.org/ih (acesso em 12-I-2012). 